\title{
FINANCIAL CONTENT OF BULGARIA HEALTH EXPENDITURE AND SOME COMPARISONS BETWEEN EU COUNTRIES
}

\author{
N. Atanasov* \\ Department of Health Management and Health Economics, Faculty of Public Health, \\ Medical University - Plovdiv, Plovdiv, Bulgaria
}

\begin{abstract}
Purpose. The aim of the study is to be provided some international comparisons of the burden and financial composition of the health expenditure for EU.

Methods. It is used descriptive and frequency statistics, graphical analyses and classical regression with OLS estimates.

Results. It was found a relatively high burden of the total current health expenditure (TCHE) as a percent of current GDP in Bulgaria (8.2\%) and for the most EU countries (Mean=8.5\%; SD=1.8\%). Positive relation between the TCHE and the GDP per capita in PPS (R=0.604; Sig. F=0.000) was established. For the period 2006-2015 the burden has got a sensible growth for seven countries which have got a significant impact on the EU's GDP forming. Even significant variation of the elements of the financial mixes it can be formed two groups of countries - with predominant share ( $>50 \%$ of TCHE) of tax financing (11 countries) and with biggest social health insurance ( 9 countries). The private sources are prevailed by the direct payments (Mean=21.8\%; $\mathrm{SD}=10.2 \%$ ). Bulgaria health expenditure financial mix differs with maximum out-of-pocket share and it has got the following description: $2.5 \%$ direct taxes; $6.7 \%$ indirect taxes; $41.9 \%$ social health insurance; $47.7 \%$ direct payments and $0.4 \%$ voluntary insurance. Conclusions. Despite domination of public sources that creates favorable effects enhancing the coverage in sector the variation and the considerable share of the direct payments for not a few countries as well as the relatively higher weights of indirect taxes limit the financial affordability, and threaten the income inequality reranking the consumers due to the out-of-pocket payments that they made. It concerns generally Bulgaria and as well as the countries with similar living standard measures, financial burden ratio and the health expenditure content.
\end{abstract}

Key words: health financing, burden of health expenditure, financial mix of health expenditure, redistributive effects of health expenditure.

\section{INTRODUCTION}

The complex economic nature of the health goods, the benefits of which are both personal and widespread on groups of individuals living in a particular region or the whole country, imposes funding methods with different origins. The different methods of accumulating funds are directed to their only source - the income with a specific way. This feature of the financial content or mix of the health expenditure causes the burden and redistributive effects on the income affecting the inequality.

\footnotetext{
*Correspondence to: Nikolay Georgiev Atanasov, Medical University - Plovdiv, V. Aprilov Blvd., 15A, Plovdiv, 4002 Faculty of Public Health,

Department of Health Management and Health Economics, E-mail: nik.atanasov@abv.bg; tel.: $+359885771262$
}

The problem of financial burden of health refers to that group of studies which try to explain how the expenditure on health relates to the economic dynamics measured commonly with the GDP growth rates. The burden can be connected also with measures of the living standard. It helps to be explored how the countries with a different wealth and a different economic potential suffer the 'price' of health. This group of studies uses complex econometric models where commonly the health expenditure is connected with the economic growth (1-7).

The problem of the content or the financing mix of health costs relates to the studies which subject is the redistributive effects i.e. they explain the burden on the financing side of the process or how the funds accumulation affects the income distribution in national economy. 
These groups of studies use rich and complicated data both aggregate and micro concerning the added value, GDP, GDP growth rates, budget revenue and health expenditure by agents or financing schemes, household health costs, household income and others. The redistributive effects are explored with specific methods measuring the changes of income inequality before and after the funds accumulation with adopted methods - direct taxes, indirect taxes (both as a government financing), social health insurance, direct payments, voluntary insurance and others (813).

\section{DATA AND METHODS}

The burden of health expenditure is measured using the ratio between the total current health expenditure (TCHE) and the current GDP. The financial content/mix is studied by the following components based on the general methods of taxation, insurance and in broad sense on the main forms for money attraction direct taxes, indirect taxes, social health insurance, direct payments and voluntary insurance (8).
ATANASOVN.

Elements with a very small relative share in total health costs or with little effect on both the financing of the sector and the redistribution of income are the corporate financing schemes and the medical savings accounts. Both forms of funding have limited effects within the EU countries and they are not considered in the study.

There is also another reason that proves the importance of that financial content of health costs. This is the difference way that the elements or methods relay to the income and income distribution. In other words the national fiscal and health policies could manage the income inequality and financial affordability with one or another description of the health expenditure financial content.

The health insurance and the direct payments represent methods that accumulate specially intended and directly spent money in the sector or they are earmarked methods. Regardless, the taxation or broadly the budget revenue methods are not direct purposed for the health sector. The earmark levies are met very rear in the modern budget practice. For that reason the mix of the direct and indirect taxes share in the financial are calculated with the next formulas:

$$
\begin{aligned}
& D T=\frac{\text { Direct } \text { Taxes Revenue }}{\text { Total Tax Revenue }} \times \frac{\text { Government Budget Financing Schemes }}{\text { Tatal Current Health Expenditure }} \\
& I T=\frac{\text { Indirect Taxes Revenue }}{\text { Total Tax Revenue }} \times \frac{\text { Government Budget Financing Schemes }}{\text { Tatal Current Health Expenditure }}
\end{aligned}
$$

The amount of direct taxes is determined as a sum of the taxes on income and wealth and the capital taxes. For its part, the amount of indirect taxes corresponds to the amount of taxes on production and imports.

The data used to conduct the survey are the values available, provided and presented by Eurostat for variables from the next thematic areas: the government financial statistics - for the tax revenue indicators for 2015; the health expenditure by financing schemes as a percentage from the TCHE for the last available 2015 .

\section{RESULTS AND DISCUSSION}

Burden of the Total Current Health Expenditure

In the EU and broadly in the Old continent, it can be seen that there is a significant burden on health costs. The total current health expenditure (TCHE) as a percent from current GDP is presented on Figure 1.

Bulgaria has got a share of TCHE in GDP of $8.2 \%$, which is close to the set's central tendency $(n=32$; Mean $=8.5 \%$; Median $=8.6 \%)$. However, the variation of the indicator is considerable (Range $=6.4 \%$; $\mathrm{SD}=1.8 \%$ ). The lowest observed value is for Romania of $4.95 \%$, Germany has got the biggest burden ratio of $11.15 \%$ in EU. Switzerland which is not EU member has got the greatest continent health burden ratio of $11.37 \%$.

The largest is the number of countries, eight, with the cost burden of health falling within the range of $6.2 \%$ to $7.5 \%$ and over $10.1 \%$. The empirical frequency distribution of the observed set of countries has two vertices. It can be seen on Figure 2 and Table 1. 


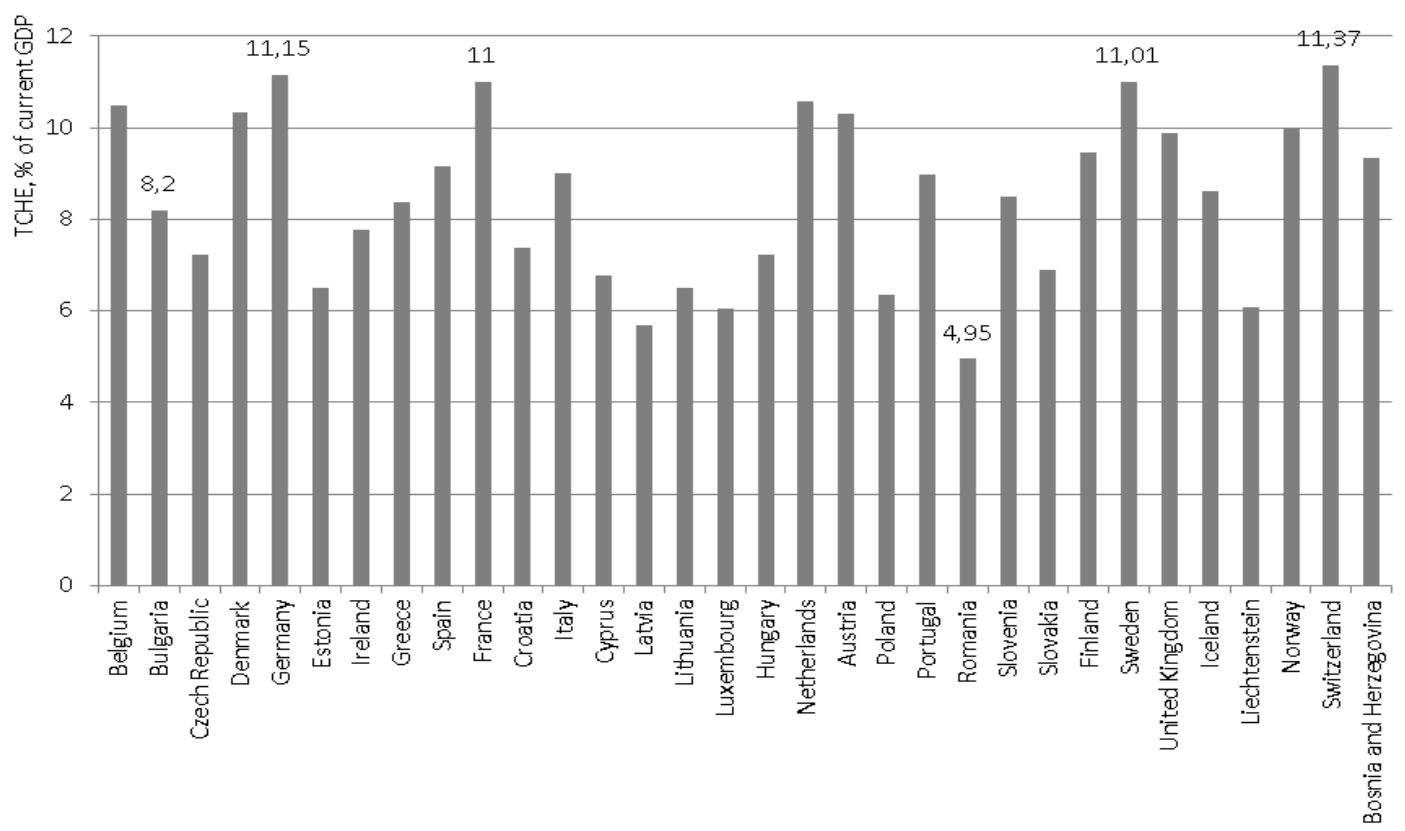

Figure 1. Total current health expenditure as a percent of GDP for 2015.

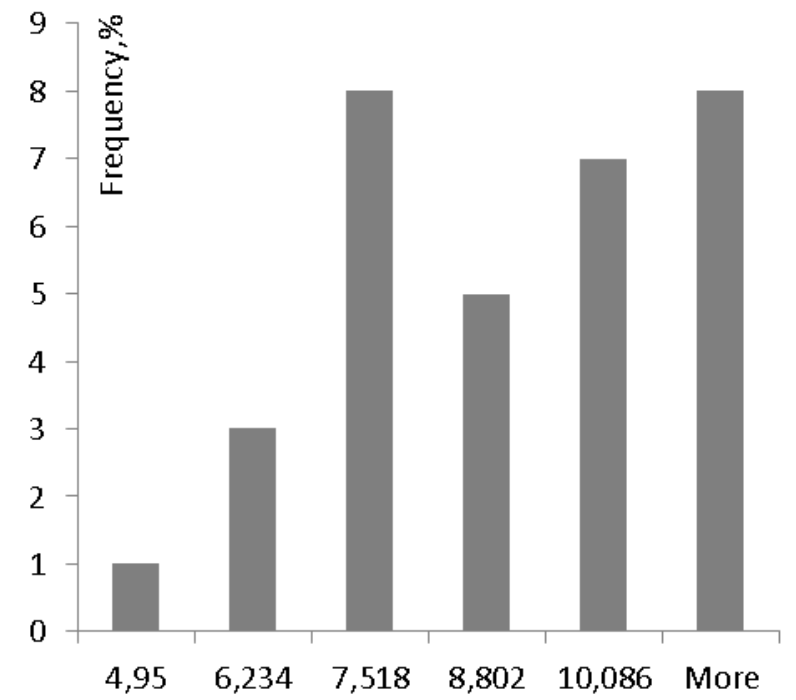

Figure 2. Empirical frequency distribution of the health expenditure burden for the observed countries $(n=32)$.

Table 1. Burden frequencies and cumulative share.

\begin{tabular}{|c|c|c|}
\hline Bin & Frequency & $\begin{array}{c}\text { Cumulative } \\
\text { \% }\end{array}$ \\
\hline 4.95 & 1 & 3,13 \\
\hline 6.23 & 3 & 12,50 \\
\hline 7.52 & 8 & 37.50 \\
\hline 8.80 & 5 & 53.13 \\
\hline 10.09 & 7 & 75.00 \\
\hline More & 8 & 100.00 \\
\hline
\end{tabular}

The higher levels of the health costs burden can be associated with an increase in living standards measures and opposite. On the next chart, we can see the dispersion of the burden ratio due to the GDP per capita in purchasing power parity index $(\mathrm{EU} 28=100)$. 


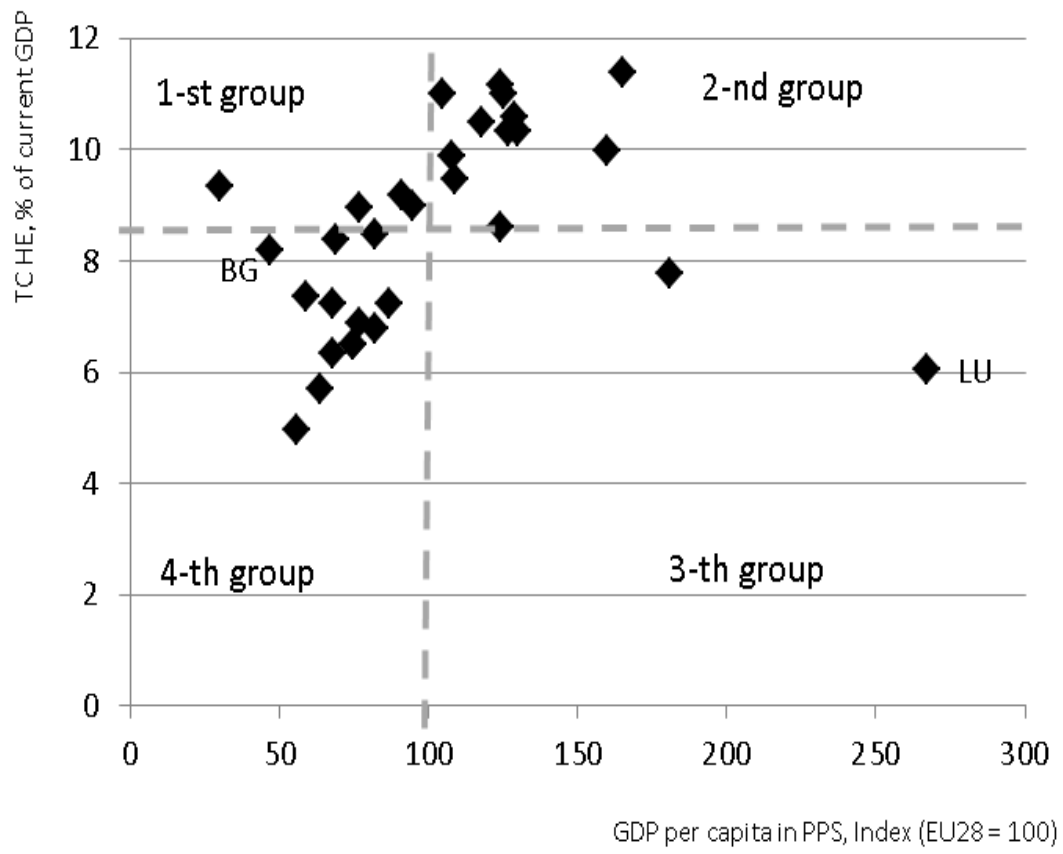

Figure 3. Health expenditure burden scatter for the set of countries for 2015.

If we exclude Luxembourg and Liechtenstein ${ }^{1}$ from the exploring the relation between the burden and living standard, then with the help of simple OLS regression we will obtain a statistically significant slope coefficient and constant, as well as correlation and determination coefficients. The OLS estimates are summarized on the next Table 2.

Table 2. Health expenditure burden and living standard measure OLS estimates.

\begin{tabular}{|c|c|c|c|}
\hline \multicolumn{2}{|l|}{ Strength of relation } & \\
\hline Multiple R & 0.604 & & \\
\hline R Square & 0.364 & & \\
\hline Standard Error & 1.449 & & \\
\hline Observations/Countries Included & 30 & & \\
\hline Sig. F & 0.000 & & \\
\hline \multicolumn{2}{|c|}{ Coefficients Estimates } & Standard Error & Sig. T \\
\hline Intercept & 5.735 & 0.77 & 0.000 \\
\hline GDP per capita in PPS & 0.0299 & 0.008 & 0.000 \\
\hline
\end{tabular}

This is an expected tendency with a confirmatory power. Numerous studies made conclusions that for countries with higher living standards, the relative share of health costs is higher than in poorer countries. This conclusion is also made with regard to the share of public funds contributed to healthcare. But it also shows that the countries from the Old continent are not only with varied indicators of the burden of health spending, but also with great differences in their funding source - the income.

\footnotetext{
${ }^{1}$ GDP per capita in PPS for Liechtenstein is not available in the database used. Luxembourg is a specific outlier with a low burden on health spending and a very high standard of living measure.
}

If we build two perpendiculars, one of the $y$ axis from the point representing the median case for health costs burden, and the other from the $\mathrm{x}$-axis from the point representing the average level of living standards in the EU, we will divide the observed set of countries into four groups. They can be described as follows:

- First group $(n=4)$ - upper and left located countries with a relatively high cost burden and relatively low living standard - Bosnia and Herzegovina (not a member of the Union), Portugal, Spain and Italy (it is important to note that the GDP per capita in PPS in this group largely varies);

- Second group $(n=12)$ - upper and right located countries with a relatively high burden ratios, but with a high GDP per capita - the Scandinavian countries, 
Germany, France, Austria, Switzerland and others;

- Third group $(\mathrm{n}=2)$ - down and right located countries with high living standard and relatively low health costs burden Luxembourg and Ireland;

- Fourth group - down and right located with low living standard and relatively high health costs burden $(n=12)$ - Central East Europe countries which group includes Bulgaria with coordinates $(8.2 ; 47)$.

The scatter in Figure 3 helps to be found another interesting fact - the number of the countries that stay very close or almost on the lines dividing on four parts the first quadrant area is not smal. For these countries small income or burden ratio changes would change the composition of the four groups. There are
ATANASOV N.

three countries in a specific 'risky state' of falling into the first group all of its with close but still lower to the median financial health burden and living standards far from the average for the Union, such as Bulgaria, Greece and Slovenia. If in these countries the TCHE continue to rise then they will soon enter the first group with relatively the heaviest burden.

If we consider the dynamics then it will be found that the burden of health expenditure remains relatively constant, and for some countries it even grows considerably. The following figure presents the burden of health expenditure in the period 2006-2015 for seven countries, with the greatest contribution to the formation of EU's GDP.

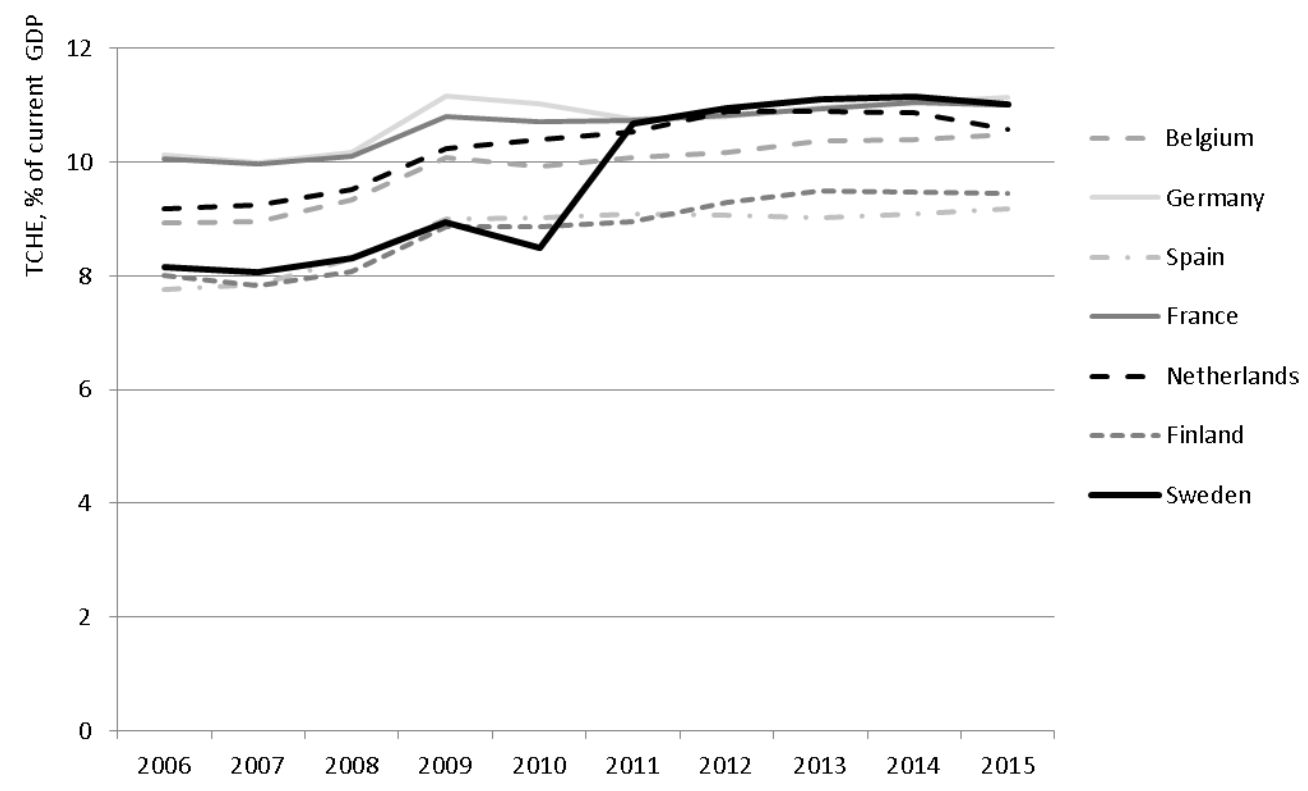

Figure 4. Dynamic rows of the health financial burden for seven countries in the period 2006-2015.

Obviously, for these member countries the burden ratios raise even the negative crisis effects on income. This finding indirectly proves the low income elasticity of the health expenditure.

\section{Financial Content of Health Expenditure}

The financial content/mix of the TCHE has a variegated picture in the Old continent. The reasons for this can be sought primarily in the fact that each country, in the frame of its national fiscal and health policies, has adopted its own financing model. Of course, the strategic goals of health authorities in the EU are probably too close, and in particular in the area of the health expenditure funding, they are intended to achieve a universal coverage with no large effects on the income inequality.
Some of the latest WHO documents, for example, recommend that goal to be pursued through the use of public funding methods strengthening the role of a social health insurance (14-15). On this basis, we should expect that health funding in the $\mathrm{EU}$ are directed to a predominant public sources share, while the private health financing methods has a lower impact. Another argument supporting such considerations is the levels of per capita income. This indicator takes one of its highest values in the Europe region that allows to be built a financial structure of the health expenditure with large public contributions. The results from public and private sources descriptive statistics confirm the mentioned above. 
Table 3. Some descriptive statistics measures of public and private mixes.

\begin{tabular}{|l|c|c|}
\hline Measure & $\begin{array}{c}\text { Public } \\
\text { Sources }\end{array}$ & $\begin{array}{c}\text { Private } \\
\text { Sources }\end{array}$ \\
\hline Mean & 72.99 & 27.01 \\
\hline Standard Error & 1.897 & 1.897 \\
\hline Median & 75.63 & 24.37 \\
\hline Standard Deviation & 10.392 & 10.392 \\
\hline Minimum & 42.62 & 14.61 \\
\hline Maximum & 85.39 & 57.38 \\
\hline $\begin{array}{l}\text { Count/Countries } \\
\text { included }\end{array}$ & 30 & 30 \\
\hline
\end{tabular}

Within the public funds, the average shares of the social health insurance (33.3\% of TCHE) and government funding are almost equalized, with a small and insignificant predominance of government funding (35.7\% of TCHE). However, these results are obtained with unweighted data, not taking into account the contribution of each country in the Europe's GDP. If the two elements are weighted with the share of the country's GDP from the common GDP probably the social health insurance schemes will prevail over the taxes because countries such as Germany and France have a very low budget funding for health, and the United Kingdom is leaving the Union.

The more detailed financial mixes of the countries can be analyzed graphically using scatter diagrams on the different elements to illustrate the tendencies. Interesting is the relationship between the public sources and the direct payments which are the major component of the private financing [8]. In Figure 5 can be seen the scattering of public funds (government and social security health financing, PHE) caused by the out-of-pocket payments (OPP). We see that the most countries are located in the upper left corner of the plot area. This could be explained with the fact that public funds predominate significantly over private and, in particular, direct payments. Another interesting fact is that the countries stay very close to the bisector line. This reflects the dependency that EU countries use, but with very little weight, other methods of private health expenditure financing different from the out-of-pocket payments, such as, for example, voluntary health insurance, companies payments, etc.

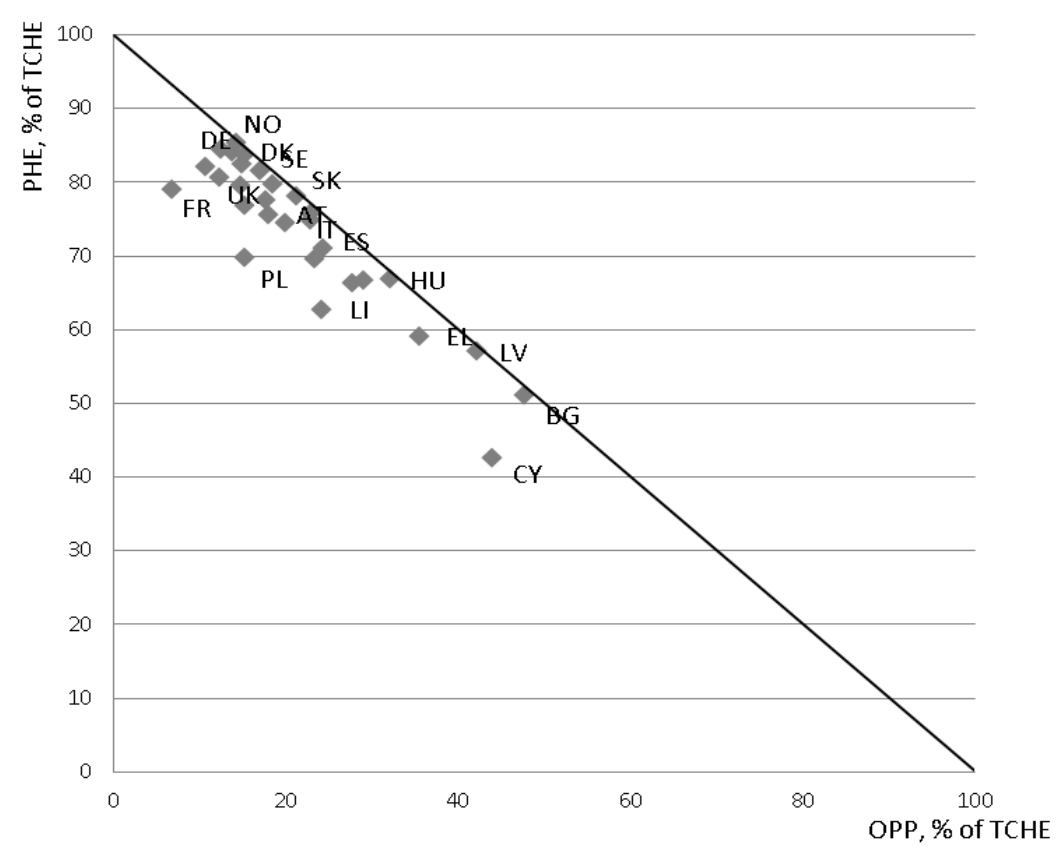

Figure 5. Public health sources and out-of-pocket payments (OPP) for 2015. 
The survey allows to be indicated several countries that have the greatest burden of direct payments. These are Bulgaria $(\mathrm{OPP}=47.7 \%)$, Cyprus, Latvia and Greece. These countries suffer significant financial burden of health considering their relatively low living standard measures (compared with the EU average). Several countries are also stay quite below the bisector line. They are also located very high in plot area. These are France, Poland and Lithuania, which have relatively the highest share of voluntary health insurance and other methods of private health expenditure financing. The Scandinavian countries, Germany, Austria, Italy, the United Kingdom and others stay closest and highest to the bisector line. These countries are built relatively highest public financing of health
ATANASOV N. expenditure with a lowest share of direct payments respectively.

Another interesting view can be made to the direction of the content of government financing schemes, i.e. the proportion of direct/indirect taxes. In recent decades, VAT has become a tax with major fiscal effect. In the same time the role of the excises has sensible increased as a tool controlling the consumption of some goods. This is also reflected in the financial mix of healthcare expenditure, with an average indirect tax weight of $18.2 \%$ (Range $=54.5 \%$; SD=14.2\%), while the mean direct tax share of the TCHE is $17.5 \% \quad$ (Range $=43.6 \% ; \quad \mathrm{SD}=16.5 \%$ ). The Figure 6 presents great variation of the taxes financing proportions.

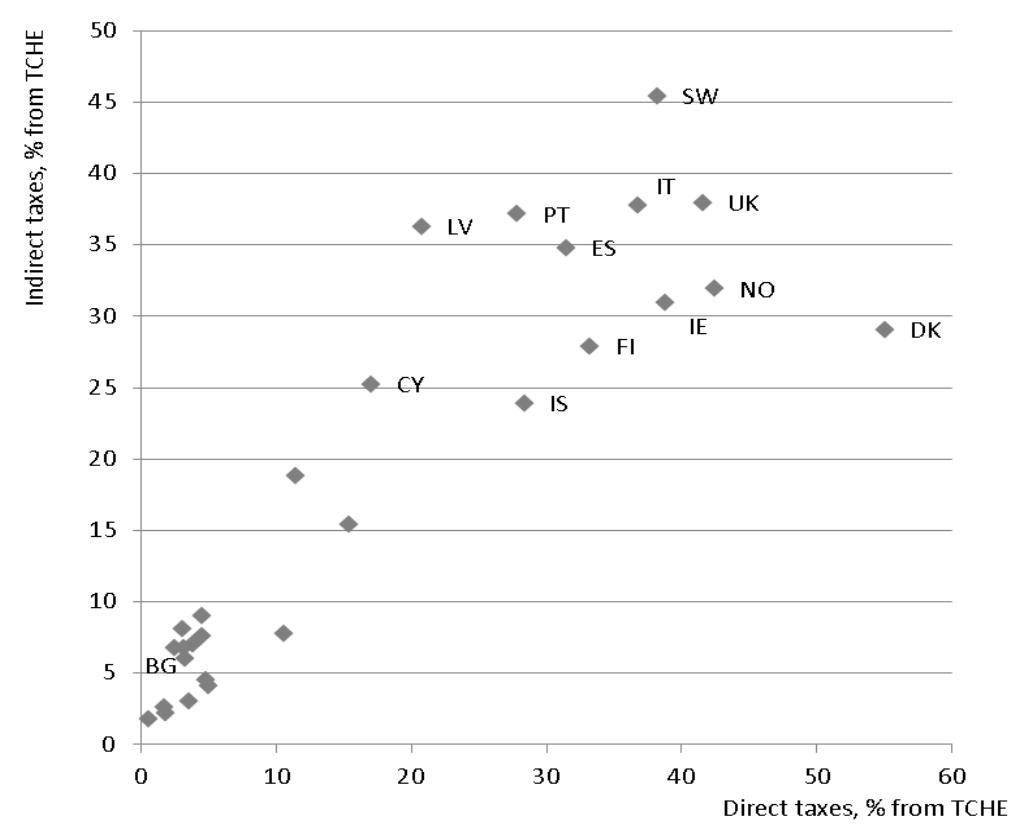

Figure 6. Participation of the direct and the indirect taxes in the health expenditure financial mix in EU for 2015.

Half of the countries have got the direct tax financing proportion less than $11.5 \% \quad(n=15)$ and less than $10.5 \% \quad(n=14)$ indirect levy respectively. Eleven countries are distinguished with a total tax burden of more than $50 \%$ form the TCHE. These are the countries located in the upper right angle of Figure 6. Sweden is the country with the biggest weight of the indirect taxes and Denmark has got the greatest proportion of direct income levy. Two other Scandinavian countries, such as Finland and Norway, also have large government funding, in which the two forms of income taxation have a relatively equal presence in the TCHE. Other Western European countries with significant government funding are Spain, Portugal and the UK. Eastern European countries with large tax funding are Latvia and Cyprus. The other countries lie in the lower left angle, being located closer to the vertical axis. These countries have a relatively low tax burden, dominated from the indirect taxation. This group includes countries like France, Germany and Luxembourg, after all, but also all Central Eastern Europe countries. The direct/indirect taxation ratio for Bulgaria is typically in the CEE group with $2.5 \%$ of direct and $6.7 \%$ of indirect taxation which corresponds to $9.2 \%$ share of the government financing schemes from the TCHE.

\section{CONCLUSIONS}

The countries from the old continent use a wide variety of methods to finance the healthcare expenditure. Something more, the countries' financial mixes of the TCHE are broadly differs among themselves in terms of 
the public and private sources and the composition within these two groups. It exists countries which use mostly a social health insurance and a small government share in their financing mixes and the opposite. We also see great diversity in the elements of government funding from countries with significant direct tax contribution to the health sector to those with higher fiscal impact of indirect forms of income taxation.

In the existing colored picture of the financial content of the TCHE, a few conclusions could be drawn for the burden of health.

In the Old continent, the burden of health expenditure, measured as a ratio of current GDP, is relatively high. For a significant part of the countries that have substantially contribution to the EU's GDP the burden increases. This process develops although the stagnation of the income caused by the last global economic crisis.

For the most observed countries, there is a significant prevalence of public sources contributed to the sector compared with the private ones. This process provides at least two effects - on the one hand, it achieves higher coverage and on the other facilitates access to health goods consumption. Moreover, the presence of more publicly-funded resources also has a more favorable effect on inequality, redistributing resources from richer to poorer.

There are clearly two dominant, characteristic groups of countries with regard to the composition of public resources - recourse to priority and even only budgetary contributions (government financing) and a defined mix of social health insurance and budget funding.

The strong variation in direct payments in not a few countries could generate at least two unfavorable effects. The first is to hamper and limit the financial affordability, and the second is a threatening the income inequality reranking the consumers due to the out-of-pocket payments that they make.

The relatively higher weights of indirect taxes in the financial mixes are another reason that creates disproportions. It affects generally the poorest consumers of health goods and thus could result in large income inequality.

The last two conclusions concern Bulgaria and as well as other countries with a similar financial mix - a high share of direct payments and in the same time a significant presence of indirect taxes both as factors that create conditions for increasing the income inequality caused by the financing of healthcare expenditure.

\section{REFERENCES}

1. Gerdtham, U. and Jönsson, B., International comparisons of health expenditure, Handbook of Health Economics, Volume 1A, Edited by Culyer, A. and Newhouse, J., Elsevier, 2000.

2. Baltagi, B. and Moscone, F., Health care expenditure and income in the OECD reconsidered: Evidence from panel data. Economic Modelling, 27:804-811, 2010.

3. McCoskey, S. and Selden, T., Health care expenditures and GDP: panel data unit root test results. Journal of Health Economics, 17:369-376, 1998.

4. Narayan, S., Narayan, P., Mishra, S., Investigating the relationship between health and economic growth: empirical evidence from a panel of 5 Asian countries. Journal of Asian Economics, 21:404-411, 2010.

5. Bloom, D., Canning, D., Sevilla, J., The effect on health on economic growth: Theory and evidence. National Bureau of Economic Research, 2001.

6. Jones, C., Why have health expenditure as a share of GDP risen so much? National Bureau of Economic Research, 2002.

7. Thomson, S. et al, Economic crisis, health systems and Health in Europe, Open University Press, 2015, pp. 51-79.

8. Wagstaff, A. et al, Equity in the finance of health care: some further international comparisons. Journal of Health Economics, 18: 263-290, 1999.

9. Doorslaer, E. et al, The redistributive effect of health care finance in twelve OECD countries. Journal of Health Economics, 18: 291-313, 1999.

10. Aronson, J.R. and Lambert, P., Decomposing the Jini coefficient to reveal the vertical, horizontal and reranking effects of income taxation. National Tax Journal, 47(2): 273294, 1994.

11. Kakwani, N., Measurement of tax progressivity: An international comparison. Economic Journal, 87: 71-80, 1977.

12. Jenkins, S., Calculating income distribution indices from microdata. National Tax Journal, 61: 139-142, 1988.

13. Mello-Sampayo, F. and Sousa-Vale, S., Financing health care expenditure in the OECD countries: evidence from a heterogeneous, cross-sectional dependent panel. Panoeconomicus, 2:207-225, 2014.

14. Resolution Priorities for health systems strengthening in the WHO European Region 2015-2020: Walking the talk on people centredness. WHO, Regional Committee for Europe, $65^{\text {th }}$ session, Vilnius, Lithuania, 1417 September 2015.

15. Sustainable health financing structures and universal coverage. WHO, Sixty-Fourth World Health Assembly, 24 May 2011. 